\title{
VARIAÇÕES DOS NÍVEIS SÉRICOS DE SÓDIO, POTÁSSIO E GLICOSE DE CÃES EM CHOQUE SÉPTICO
}

\author{
SODIUM, POTASSIUM AND GLUCOSE SERUM LEVELS \\ CHANGES IN DOGS WITH ENDOTOXIC SHOCK
}

\author{
Leonardo Pinto Brandão ${ }^{1}$ Mitika Kuribayashi Hagiwara ${ }^{2}$ Márcia Mery Kogika ${ }^{3}$ \\ Júlia Yuzuki Habu Ikesaki ${ }^{4}$ Reimy Kawahara ${ }^{4}$ Vera Assunta Battistini Fortunato Wirthl ${ }^{4}$
}

RESUMO

Foram avaliados os níveis séricos de sódio, potássio e glicose em trinta e cinco cães, machos e fêmeas, que se apresentaram em estado de choque séptico decorrente da gastrenterite hemorrágica, antes e após terapia sintomática (Ringer com lactato de sódio e glicose), com a finalidade de se determinar a melhora clínica obtida. Observou-se que 74,2\% dos animais apresentavam hipocalemia, 57,1\% hipoglicemia e 60\% discreta hiponatremia, quando da primeira colheita. Após 2 horas da instituição da terapia sintomática, observou-se que a hipopotassemia ainda persistia, porém a hipoglicemia fora suficientemente corrigida (apenas 5,8\% mantiveram-se hipoglicêmicos). Concluise que a terapia sintomática é efetiva para a correção dos valores glicêmicos, porém não é capaz de repor a deficiência de potássio apresentada por estes animais, devendo ser então acrescida deste ion.

Palavras-chave: choque séptico, potássio, sódio, glicose, gastrenterite, cães.

\section{SUMMARY}

In order to evaluate sodium, potassium and glucose serum levels changes in dogs with septic shock, thirty-five young dogs of both sexes presenting hemorragic gastroenteritis and signs of septic shock were studied. Hypokalemia was observed in $74.2 \%$, hypoglicemia in $57.1 \%$ and mild hyponatremia in $60 \%$ of the animals. Two hours after therapy (Ringer's sodium lactate solution and glucose), glucose serum levels increased, but hypokalemia was still present. This study revealed that the therapy was effective to increase the glucose serum levels but, it was not able to correct the hypocalemia, and therefore, this ion have to be add in order to obtain success in the treatment of this condition.
Key words: septic shock, potassium, sodium, glucose, gastroenteritis, dogs.

\section{INTRODUÇÃO}

A liberação, na corrente sangüínea, de substâncias capazes de sensibilizar o organismo (endotoxinas) leva à produção de substâncias mediadoras do processo inflamatório, causando uma "Síndrome de Resposta Inflamatória Sistêmica" ou choque séptico, o que resulta na vasodilatação periférica, acompanhada do aumento da permeabilidade vascular. Esse processo ocasiona a diminuição do volume do fluido intravascular que, associado à liberação de um fator depressor do miocárdio (produzido pelo pâncreas isquêmico), resulta na redução drástica da perfusão sangüínea tecidual, causando isquemia, hipóxia de vários órgãos e morte do animal (CALVERT \& GREENE, 1986; GROOWIN \& SCHAER, 1989; PURVIS \& KIRBY, 1994).

As bactérias Gram negativas, tais como Escherichia coli, Proteus ssp, Pseudomonas ssp e Klebsiella ssp, de acordo com BRADLEY (1979) e CALVERT \& GREENE (1986), são as mais frequientemente associadas ao desencadeamento do quadro de choque endotóxico. Elas liberam na circulação sangüínea um fosfolipídeo $\mathrm{A}$ da parede celular, que se liga a receptores não específicos da

\footnotetext{
${ }^{1}$ Bolsista de iniciação científica PIBIC-CNPq do Departamento de Clínica Médica da Faculdade de Medicina Veterinária e Zootecnia da Universidade de São Paulo. Rua Lavínio Salles Arcuri, 788 Vila Espanhola, 02564-000, São Paulo, SP. E-mail: leobrandao@yahoo.com.br. Autor para correspondência.

${ }^{2}$ Professor Titular do Departamento de Clínica Médica da FMVZ/USP.

${ }^{3}$ Professor, Doutora do Departamento de Clínica Médica da FMVZ/USP.

${ }^{4}$ Médico Veterinário contratado do Hospital Veterinário da FMVZ/USP. 
membrana celular do endotélio vascular e também em receptores específicos da membrana de macrófagos, desencadeando uma resposta inflamatória que envolve vários mediadores (TNF- $\alpha$ : fator de necrose tumoral, interleucinas 1 e 6 , interferon e fator de agregação plaquetária). As células endoteliais sensibilizadas pelas endotoxinas iniciam o processo de degradação do ácido aracdônico, gerando a cascata de produção das prostaglandinas e dos leucotrienos (PURVIS \& KIRBY, 1994).

Paralelas à disfunção cardiovascular (hipotensão), ocorrem alterações do equilíbrio hidreletrolítico e ácido-básico que contribuem para a progressão do quadro mórbido. Os íons sódio e potássio desempenham papel fundamental no organismo, como a regulação da pressão oncótica cristalóide, a manutenção do equilíbrio ácido-básico e dos potenciais elétricos de membrana plasmática, a transmissão dos impulsos nervosos e os processos de absorção de monossacarídeos, aminoácidos, pirimidina e sais biliares (DiBARTOLA 1989; DiBARTOLA \& DeMORAIS, 1992).

A alteração do equilíbrio ácido-básico ocorre devido ao quadro de hipóxia tecidual, decorrente da diminuição da perfusão sangüínea, favorecendo a obtenção de energia pela via glicolítica anaeróbica, o que ocasiona o aumento da concentração de ácido lático e a progressiva instalação de acidose metabólica (BRADLEY, 1979; GROOWIN \& SCHAER, 1989).

Dentre as alterações metabólicas observadas no choque séptico, a hipoglicemia progressiva, decorrente do incremento no consumo de glicose, da depleção de estoques hepáticos e, ainda, da intensa utilização da via glicolítica anaeróbica, favorece o êxito letal do processo, quando não há instituição de uma terapia adequada (HINSHOW et al., 1974; MILLER et al., 1980).

Dentre as causas infecciosas que podem evoluir para o choque séptico na espécie canina, destacam-se aquelas relacionadas às infecções do trato urinário e reprodutivo, aos processos de cavidade abdominal (peritonites), trato respiratório e, de forma bastante freqüente, os processos gastrentéricos, principalmente a parvovirose, que causa intensa lesão da mucosa intestinal, favorecendo a invasão de bactérias para a circulação sistêmica (CALVERT \& GREENE, 1986; PURVIS \& KIRBY, 1994).

O presente estudo teve como objetivo determinar as variações dos níveis séricos de sódio, potássio e glicose em pacientes (cães) com gastrenterite hemorrágica, em choque séptico, antes e após terapia sintomática (Ringer com lactato de sódio e glicose) com a finalidade de se avaliar a melhora clínica obtida, possibilitando a instituição de terapia adequada.

\section{MATERIAL E MÉTODOS}

Foram estudados trinta e cinco cães, machos e fêmeas, com idade variando entre 2 a 6 meses, com um quadro de choque séptico, conseqüente da gastrenterite hemorrágica (diagnóstico presuntivo de parvovirose), provenientes do Serviço de ProntoAtendimento Médico do Departamento de Clínica Médica/HOVET da Faculdade de Medicina Veterinária e Zootecnia da Universidade de São Paulo, durante o período de fevereiro de 1995 a maio de 1996.

De cada animal foram colhidas amostras de sangue, por punção das veias jugular ou cefálica, em tubos siliconizados ${ }^{\mathrm{a}}$ para a realização do hemograma e das determinações bioquímicas. Para a realização da leucometria, $2 \mathrm{ml}$ de sangue foram colocados em tubos contendo anticoagulante $\left(\mathrm{Na}_{2}-\right.$ EDTA), sendo o material processado segundo técnica rotineiramente empregada no Laboratório de Análises Clínicas do Departamento de Clínica Médica/HOVET da Faculdade de Medicina Veterinária e Zootecnia da Universidade de São Paulo.

O soro sangüíneo, no qual se procedeu a determinação da glicemia e de eletrólitos, foi obtido após a separação do coágulo. Para a determinação da glicemia, utilizou-se método enzimático colorimétri$\mathrm{co}^{\mathrm{b}}$ em analisador automático ${ }^{\mathrm{c}}$, e para a determinação de sódio e potássio séricos utilizou-se fotômetro de chama ${ }^{\mathrm{d}}$. Duas horas após o início da fluidoterapia, foram novamente avaliados os níveis glicêmicos em 17 dos cães e os níveis de sódio e potássio em 16 animais. A terapia sintomática utilizada nestes pacientes consistia de infusão intravenosa de solução cristalóide (Ringer com lactato de sódio) na dose de $90 \mathrm{ml} / \mathrm{kg}$ na primeira hora, e então $10-12 \mathrm{ml} / \mathrm{kg} / \mathrm{hora}$, acrescida de dextrose $50 \%$ na dose de 0,5 a $1,0 \mathrm{ml} / \mathrm{kg} / \mathrm{hora}$, com o objetivo de manter os níveis glicêmicos em torno de 100 a $200 \mathrm{mg} / \mathrm{dl}$ (GROOWIN \& SCHAER, 1989; PURVIS \& KIRBY, 1994). O diagnóstico de choque séptico foi baseado na causa que desencadeou o processo (gastrenterite hemorrágica) e no quadro sintomático apresentado pelos animais (hipotensão, taquicardia, hipotermia, diminuição do tempo de preenchimento capilar), tendo-se utilizado para avaliação da melhora clínica a diminuição ou ausência dos mesmos.

$\mathrm{O}$ teste $\mathrm{t}$ de student não pareado foi utilizado para análise das variações das concentrações séricas de sódio, potássio e glicose, antes e 2 horas após a instituição da terapia.

\section{RESULTADOS E DISCUSSÃO}

A leucopenia com desvio à esquerda, observada na grande maioria dos cães $(88,6 \%)$, demonstrada na figura 1 , é decorrente da ação direta da 


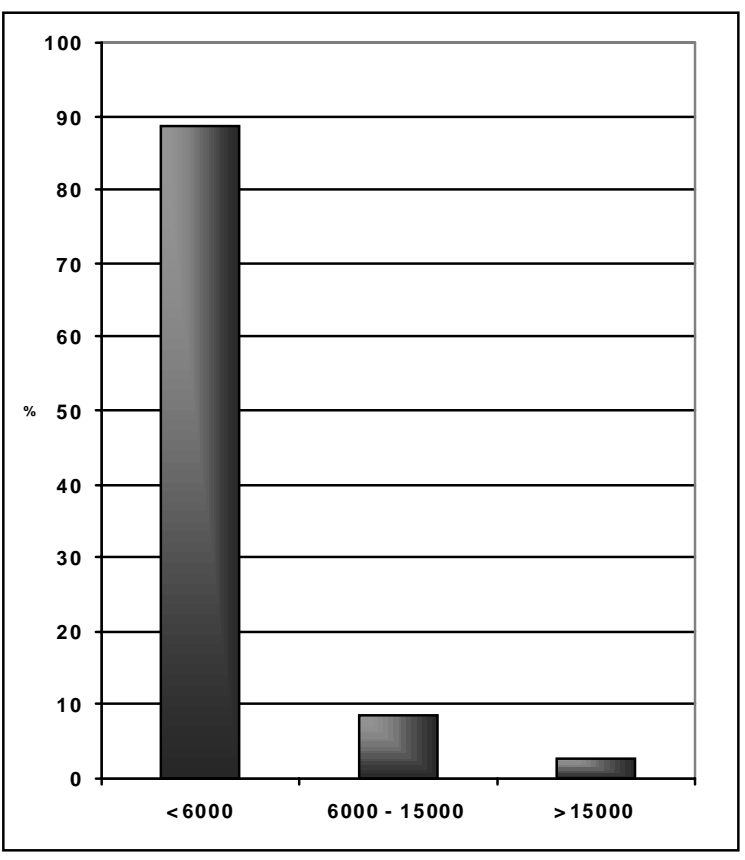

Figura 1 - Distribuição relativa dos cães com gastrenterite hemorrágica em choque séptico, de acordo com a leucometria (leucócitos/mm³). São Paulo, 1996.

endotoxina bacteriana sobre a função hematopoiética da medula óssea, sendo comumente observada nos processos septicêmicos, de acordo com BRADLEY (1979) e COLES (1986).

A endotoxina bacteriana compromete a cadeia respiratória atuando diretamente sobre a mitocôndria e, assim, desenvolve-se rapidamente a depleção dos estoques de glicogênio e a maior utilização da via glicolítica anaeróbica para a manutenção da fonte energética (ATP), caracterizando este período como a fase hipodinâmica do choque (CALVERT \& GREENE, 1986; GROOWIN \& SCHAER, 1989). Segundo HINSHOW et al. (1974) e MILLER et al. (1980), a hipoglicemia é considerada como uma das principais responsáveis pelo óbito do animal, devendo esta deficiência ser reconhecida e corrigida. No presente estudo, $57,1 \%$ dos cães apresentavam concentrações séricas de glicose abaixo dos valores de referência, justificando-se, de certa forma, o estado crítico apresentado pela maioria dos cães.

Paradoxalmente, em $14,3 \%$ dos cães foi detectada hiperglicemia (valor máximo observado de $182 \mathrm{mg} / \mathrm{dl}$ ). Sugere-se que nesses animais houve o incremento da glicogenólise, provavelmente promovida pela liberação de catecolaminas e de hormônios hiperglicemiantes, freqüentemente observada no início da instalação do choque, considerada como a fase hiperdinâmica do processo, que antecede a hipodinâmica. Portanto, o prognóstico para esses animais tende a ser mais favorável do que aquele dos animais hipoglicêmicos. A avaliação da glicemia em 17 cães, 2 horas após o início da terapia sintomática (Ringer com lactato de sódio e glicose) demonstra que a terapia rotineiramente empregada parece ser satisfatória na correção dos níveis glicêmicos, havendo redução no número de animais hipoglicêmicos e aumento dos hiperglicêmicos (figura 2).

Quanto à avaliação dos eletrólitos, a hipopotassemia (valores séricos de potássio inferiores a $4,4 \mathrm{mEq} / \mathrm{L}$ ) foi a alteração mais evidente observada no presente estudo, tendo-se demonstrado que $74,2 \%$ dos animais apresentavam valores abaixo da faixa de normalidade, coincidindo com os relatos de vários pesquisadores (GROOWIN \& SCHAER, 1989; PURVIS \& KIRBY, 1994; WILLARD, 1989) que consideram a hipopotassemia o distúrbio eletrolítico mais significante no choque séptico decorrente da gastrenterite. Nesses animais, o distúrbio ocorre como conseqüência da acentuada perda gastrentérica e, em menor magnitude, da perda renal de potássio devido à ativação do sistema renina-angiotensinaaldosterona, e ainda pela diminuição da ingestão do íon. Em 16 cães, a avaliação dos níveis séricos de potássio foi realizada novamente 2 horas após o

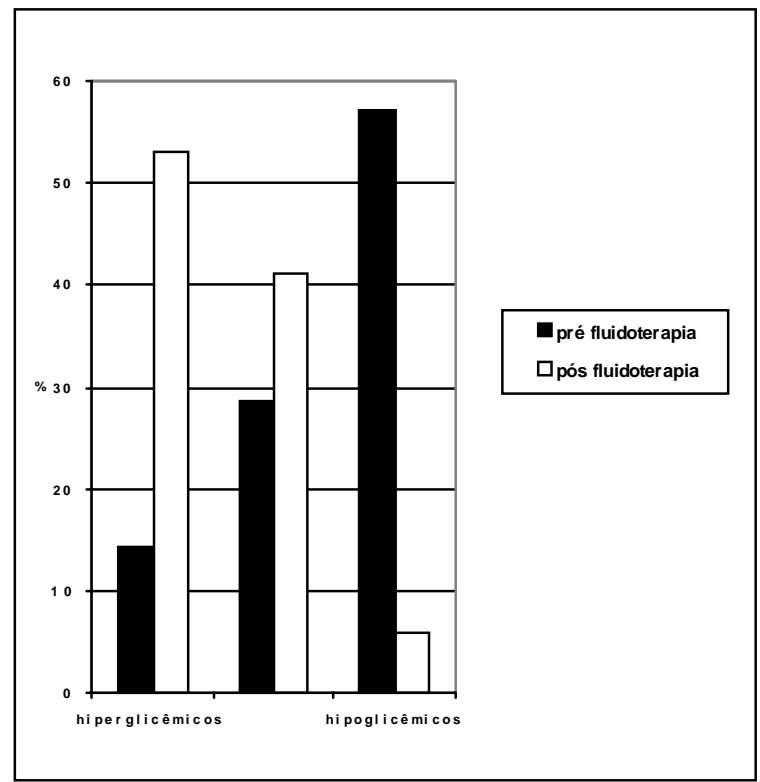

Figura 2 - Distribuição relativa de cães hipoglicêmicos (valores séricos de glicose inferiores a $80 \mathrm{mg} / \mathrm{dl}$ ), normoglicêmicos (valores séricos de glicose entre 80 a $120 \mathrm{mg} / \mathrm{dl}$ ) e hiperglicêmicos (valores séricos de glicose superiores $120 \mathrm{mg} / \mathrm{dl}$ ), com gastrenterite hemorrágica, em choque séptico, antes e após fluidoterapia de reposição. São Paulo, 1996. 
início da terapia, como configurado na figura 3 , onde se demonstrou que todos os animais ainda apresentavam hipopotassemia. Esta condição já mencionada por alguns pesquisadores que observaram o declínio da concentração sérica de potássio após instituição de fluidoterapia, mesmo considerando-se a administração da solução de Ringer com lactato de sódio, que contém potássio na sua composição (DiBARTOLA \& DeMORAIS, 1992).

Variações intensas ou relevantes dos níveis séricos de sódio não são freqüentemente relatadas no choque séptico, talvez devido ao fato da maior disponibilidade desse íon no meio intravascular (COLES, 1986). A hiponatremia detectada em $62 \%$ dos cães não foi considerada grave, uma vez que os valores mantiveram-se próximos aos limites inferiores de normalidade. Mesmo após a fluidoterapia, não foram constatadas alterações significantes em relação à concentração sérica de sódio, sugerindo-se que a fluidoterapia não tenha interferido nos níveis séricos desse íon (figura 4).

Conclui-se, portanto, que a terapia sintomática é efetiva para a correção dos valores glicêmicos, porém não é capaz de repor a deficiência de potássio apresentada por estes animais, devendo ser então acrescida deste íon.

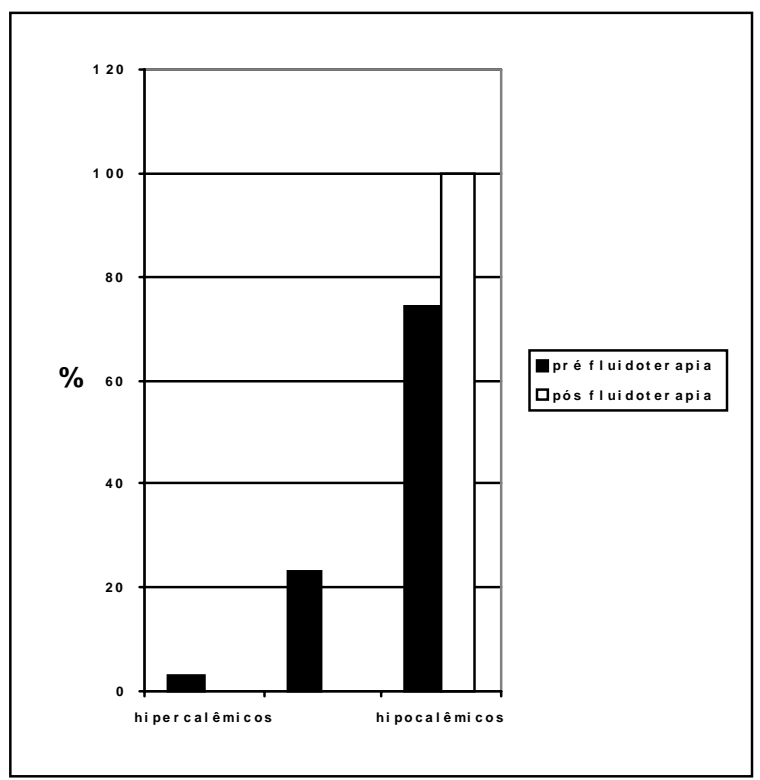

figura 3 - Distribuição relativa de cães hipocalêmicos (valores séricos de potássio inferiores a 4,4 $\mathrm{mEq} / \mathrm{L}$ ), normocalêmicos (valores séricos de potássio entre 4,4 e 5,6 $\mathrm{mEq} / \mathrm{L}$ ) hipercalêmicos (valores séricos de potássio superiores a 5,6 mEq/L), com gastrenterite hemorrágica, em choque séptico, antes e após fluidoterapia de reposição. São Paulo, 1996.

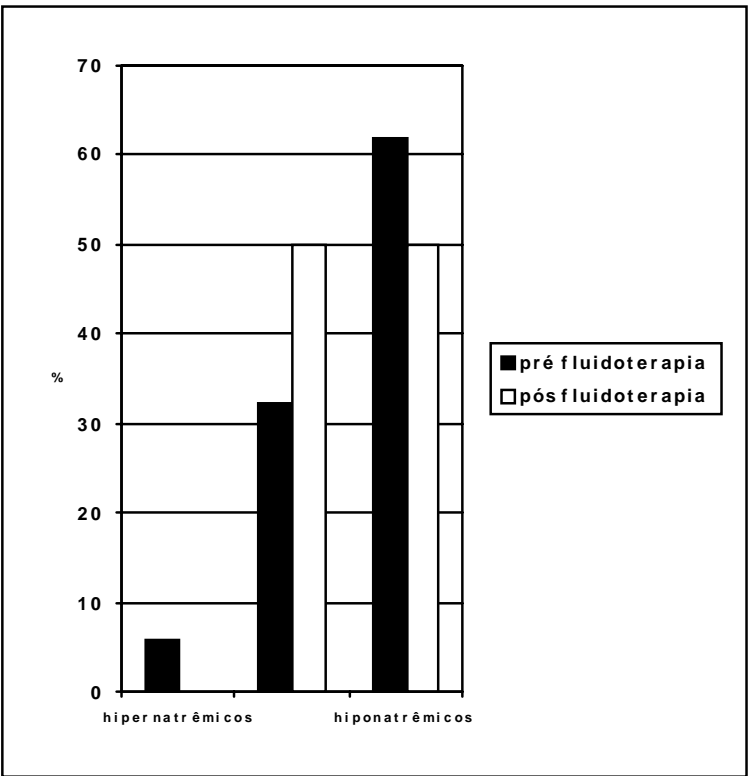

figura 4 - Distribuição relativa de cães hiponatrêmicos (valores séricos de sódio inferiores a 141,1 mEq/L), normonatrêmicos (valores séricos de sódio entre 141,1 e 152 $\mathrm{mEq} / \mathrm{L}$ )e hipernatrêmicos (valores séricos de sódio superiores a $152 \mathrm{mEq} / \mathrm{L}$ ), com gastrenterite hemorrágica, em choque séptico, antes e após fluidoterapia de reposição. São Paulo, 1996.

\section{AGRADECIMENTOS}

Ao $\mathrm{CNPq}$ pelo aporte financeiro e todo corpo de professores, pós-graduandos, médicos veterinários contratados, residentes, alunos e funcionários que integram o HOVET/USP.

\section{FONTES DE AQUISIÇÃO}

a - Tubos siliconizados Vacutainer ${ }^{\circledR}$. Becton Dickinson Indústria Cirúrgica Ltda. Curitiba, PR.

b - Kit glicose Merck System. Merck S. A. Indústrias Químicas. São Paulo, SP.

c - Analisador automático Technicon RA-100. Bayer S.A. São Paulo,SP.

d - Fotômetro de chama Fc-130 CELM. CELM Companhia Equipadora de Laboratórios Modernos. Barueri, SP.

\section{REFERÊNCIAS BIBLIOGRÁFICAS}

BRADLEY, S.G. Celular and molecular mechanisms of action of bacterial endotoxin. Annual Review of Microbiology, v. 33, p. 67-94, 1979.

CALVERT, C.A., GREENE, C.E. Bacteremia in dogs: diagnosis, treatment and prognosis. The Compendium on Continuing Education for Practicing Veterinarian, v. 8, n. 3, p. 179$186,1986$.

COLES. Veterinary Clinical Pathology, 4. ed. Philadelphia: Saunders, 1986. 566 p.

DiBARTOLA, S.P. Hyponatremia. Veterinary Clinics of North America: Small Animal Practice, v. 19, n. 2, p. 215-230, 1989.

Ciência Rural, v. 29, n. 4, 1999. 
DiBARTOLA, S.P., DeMORAIS, H.S.A. Disorders of potassium: hypokalemia and hyperkalemia. In: DiBARTOLA, S.P Fluidtherapy in small animal practice. Philadelphia: Saunders, 1992. Cap. 4, p. 89-115.

GROOWIN, J.K., SCHAER, M. Septic shock. Veterinary Clinics of North America: Small Animal Practice, v. 19, n. 6, p. 1239-1258, 1989.

HINSHOW, I.B., PEYTON, M.D., ARCHER, L.T., et al. Prevention of death in endotoxin shock by glucose administration. Surgery, Gynecology \& Obstetrics, v. 139, p. 851-858, 1974 .
MILLER, S.I., WALLACE, R.J., et al. Hypoglicemia as a manifestation of sepsis. The American Journal of Medicine, v. 68 , p. $649-654,1980$.

PURVIS, D., KIRBY, R. Systemic inflamatory response syndrome: septic shock. Veterinary Clinics of North America: Small Animal Practice, v. 24, n. 6, p. 1225-1247, 1994.

WILLARD, D.M. Disorders of potassium homeostasis. Veterinary Cxlinics of North America: Small animal Practice. v. 19, n. 2, p. 241-263, 1989.

Ciência Rural, v. 29, n. 4, 1999. 